\title{
Erratum
}

Psychopharmacology (1984) 84:231-236

\section{Tobacco withdrawal symptoms: an experimental analysis}

\author{
Dorothy K. Hatsukami ${ }^{1}$, John R. Hughes ${ }^{2}$, Roy W. Pickens ${ }^{3}$, and Dean Svikis ${ }^{4}$ \\ ${ }^{1}$ University of Minnesota, Department of Psychiatry, Minneapolis, MN 55455, USA \\ 2 University of Vermont, Department of Psychiatry, Burlington, VT 05405, USA \\ ${ }^{3}$ Addiction Research Center, Baltimore, MD 21224, USA \\ ${ }^{4}$ Johns Hopkins, Francis Scott Key Medical Center, Balitmore, MD 21224, USA
}

In this article the mean total $\mathrm{kcal} /$ day (S.E.) were reported as 1397 (101) during lib smoking and 1651 (127) during cigarette abstinence for the experimental group; and $1436(153)$ and 1345 (126) during similar time periods, respectively, for the control group. These reported results were incorrect and based on caloric intake only for breakfast and lunch and not for the total day. The correct total mean $\mathrm{kcal} /$ day (S.E.) are 2799.38 (207.16) and $3301.60(260.30)$ during ad lib smoking and cigarette deprivation, respectively, for the experimental group and
2849.50 (337.41) and 2693.14 (271.43) for the respective time periods for the control group. To test for significant withdrawal effects, a one-tailed Student's $t$-test was undertaken on the change score between baseline and abstinence. Similar to the results in the original study, there was a significant increase in caloric intake subsequent to cigarette abstinence in the experimental group when compared to the control group $(t=3.58, d f=25, P \leq$ $0.001)$. 